\title{
Endogenous Cortisol Regulates Immunoglobulin E-dependent Late Phase Reactions
}

Richard F. Herrscher, ${ }^{*}$ Candace Kasper, ${ }^{*}$ and Timothy J. Sullivan

*Department of Internal Medicine, Division of Allergy and Immunology, ${ }^{\ddagger}$ Department of Pathology, Division of Dermatopathology, and

${ }^{8}$ Departments of Internal Medicine and Microbiology, University of Texas Southwestern Medical Center, Dallas, Texas 75235

\begin{abstract}
To investigate the impact that physiological variation in serum cortisol has on IgE-mediated events, 10 atopic subjects underwent cutaneous antigen challenge with measurement of the early phase wheal (EPW) at 20 min and the late phase reaction (LPR) at $6 \mathrm{~h}$. All subjects were challenged during control conditions between 8:00 and 9:00 a.m. Repeat challenges were performed in five subjects at 6:00 p.m. and in eight subjects after ingestion of metyrapone, a specific inhibitor of cortisol synthesis. Compared with control values, mean serum cortisol was suppressed in the evening and after metyrapone $(P<0.05$ all time points). No effect was seen on the EPW, but mean LPR diameters at three antigen dilutions were significantly increased by cortisol suppression $(P<0.05)$. Replacement doses of hydrocortisone given in the evening and with metyrapone abrogated these increases. Blinded analysis of LPR biopsies from cortisol-suppressed subjects revealed increases in leukocytoclasis $(P \leq 0.0001)$, interstitial leukocytes $(P \leq 0.01)$, and eosinophils $(P \leq 0.04)$. These results indicate that physiological levels of serum cortisol can regulate IgE-dependent cutaneous inflammation by affecting the expression of cellular events at late phase sites. (J. Clin. Invest. 1992. 90:596-603.) Key words: metyrapone $\cdot$ hydrocortisone $\cdot$ diurnal $\bullet$ inflammation • skin
\end{abstract}

\section{Introduction}

Beginning in the late 1930s when glucocorticoids were first isolated and identified, it was widely believed that these compounds protected an organism during periods of stress by enhancing normal defense mechanisms and maintaining physiological homeostasis $(1,2)$. When the antiinflammatory effects of steroids were recognized, investigators had difficulty accepting these actions as protective. The ensuing controversy led to the concept of separate glucocorticoid effects: those occurring at normal physiological concentrations and those occurring only at large pharmacological doses $(3,4)$. To keep the early theories of glucocorticoid action intact, all antiinflammatory and immunosuppressive actions have until recently been relegated to a nonphysiological role. By the 1970s numerous stud-

Address correspondence to Timothy J. Sullivan, M. D., Internal Medicine/Allergy Division, University of Texas Southwestern Medical Center, 5323 Harry Hines Boulevard, Dallas, TX 75235-8859.

Received for publication 14 October 1991 and in revised form 2 March 1992.

J. Clin. Invest.

(C) The American Society for Clinical Investigation, Inc.

0021-9738/92/08/0596/08 $\$ 2.00$

Volume 90, August 1992, 596-603 ies in isolated cell systems (for review see reference 5) had demonstrated that the majority of glucocorticoid effects were in fact suppressive, not enhancing as had been predicted from the early theories. Many of these observations came from immunologic systems using physiological concentrations of glucocorticoids.

In 1984, Munck et al. (5) published a restatement of the hypothesis on glucocorticoid actions. They felt that the primary role of glucocorticoids was not to protect the organism from stress but to protect against host defense mechanisms activated by stress. In their view glucocorticoids were fulfilling a central regulatory role meant to keep the destructive forces of host defenses, such as the immune system, at bay once they became activated (5). Several studies, most in experimental animals, have corroborated this theory by demonstrating various immunoregulatory actions of endogenous glucocorticoids in whole systems (6-9).

The importance of endocrine-immunoregulation has been bolstered by evidence supporting a bidirectional feedback between the immune system and the hypothalamic-pituitaryadrenal axis. This evidence initially came from the observation that supernatants of activated peripheral blood leukocytes contained factors that increased plasma corticosterone levels when injected into rats (10). More recent work suggests that the immune system is capable of positive feedback on the hypothalamic-pituitary-adrenal axis via the release of several cytokines (including IL-1, IL-6, and tumor necrosis factor- $\alpha$ ) that act to increase circulating cortisol levels by inducing corticotropinreleasing hormone synthesis and secretion from the hypothalamus (11-13). This capacity for bidirectional feedback between the immune and neuroendocrine systems creates a situation where cortisol could tightly regulate important immune functions.

In humans, cortisol is secreted in a diurnal pattern, with serum levels typically rising above $20 \mu \mathrm{g} / \mathrm{dl}$ in the early morning hours and falling below $5 \mu \mathrm{g} / \mathrm{dl}$ in the evening (14). The immunologic consequences of this variation are poorly understood. Asthma, now recognized as an inflammatory disease (15), is characterized by nocturnal exacerbations (16). It has been suggested that this phenomenon is related at least in part to the fall in cortisol levels seen at night $(17,18)$, although efforts to demonstrate this conclusively have not been successful (19). Circadian variation in rhinitis and immediate cutaneous responses to antigen, 48/80, and histamine have also been described, but none have been linked directly to changes in endogenous cortisol (20-22).

In man, IgE-dependent mast cell stimulation typically results in a biphasic clinical response. The immediate or early phase response is largely a product of histamine release and, in contrast to the late phase, is felt to be relatively steroid resistant (23). The late phase response is known to occur in a variety of tissues and is widely used as a model for studying chronic aller- 
gic disease states. The cutaneous late phase appears $4-6 \mathrm{~h}$ after antigen challenge and may last more than $24 \mathrm{~h}$. Physically it appears as a tender, indurated, and erythematous lesion. Histologically it is characterized by the sequential appearance of neutrophils, eosinophils, and lymphocytes into a mixed cellular infiltrate (24-26). In this study, we investigated the effect that physiological variation in endogenous cortisol has on the physical and histological expression of IgE-dependent cutaneous reactions.

\section{Methods}

Subjects and study design. Nine males and one female, ages $23-43 \mathrm{yr}$ (mean $28 \mathrm{yr}$ ), were selected for study after giving written informed consent. All subjects demonstrated an IgE-dependent biphasic response, early phase wheal (EPW) ${ }^{1}$ and late phase reaction (LPR), to intradermal antigen challenge. None had ever received immunotherapy. Subjects were instructed to avoid all medications $\geq 3 \mathrm{~d}$ before being studied. The study involved two phases, both designed to manipulate subjects' cortisol levels, with effects determined by the EPW and LPR response to cutaneous antigen challenge. This study was approved by the Institutional Review Board at the University of Texas Southwestern Medical Center.

Antigen challenges. In each subject, one antigen from a single extract lot was used for all cutaneous challenges. Antigens supplied by Hollister-Stier (Spokane, WA) included mountain cedar ( $500 \mathrm{pnu} / \mathrm{ml}$ ), ragweed (500 pnu/ml, $0.62 \mu \mathrm{g} / \mathrm{ml}$ antigenE), Aspergillus fumigatas $(1,000 \mathrm{pnu} / \mathrm{ml})$, and those supplied by Berkeley Biologicals (Berkeley, CA) included Dermatophagoides farinae and pteronyssinus (1:5,000 $\mathrm{wt} / \mathrm{vol}, 100 \mathrm{au} / \mathrm{ml}$ ). Antigens were diluted with phenol-saline (Hollister-Stier) to a concentration that produced a $10 \times 10 \mathrm{~mm}$ EPW (first dilution) and then serially 10 -fold $\times 2$ (second and third dilutions). Antigen challenges were performed with these three dilutions, determined per subject, in duplicate by injecting $0.025 \mathrm{ml}$ into the volar surface of the forearm with a 0.5 -ml allergen syringe (Becton Dickinson Co., Mountain View, CA). For each experiment, subjects were challenged with fresh dilutions $\geq 3 \mathrm{~d}$ apart (mean $=12 \mathrm{~d}$ ), and extreme care was taken to inject at new forearm sites.

Phase 1 diurnal variation experiments. In these experiments cortisol levels were allowed to follow the normal diurnal pattern, except when replaced by hydrocortisone (HC, The Upjohn Company). Antigen challenges, in five subjects, were performed on separate occasions at 8:00 a.m., 6:00 p.m., and 6:00 p.m. $30 \mathrm{~min}$ after ingestion of $10 \mathrm{mg}$ (three subjects) or $20 \mathrm{mg}$ (two subjects) of HC. Differences in HC dosage were based on lean body weight.

Phase 2 pharmacological modulation experiments. In these experiments cortisol levels were depleted by metyrapone (MTP) (CIBA, Pharmaceutical Company, Summit, NJ), a specific inhibitor of cortisol synthesis that acts by reversibly blocking the 11-hydroxylation of 11deoxycortisol in the adrenal cortex (27). Eight subjects underwent antigen challenge between 8:00 and 9:00 a.m. during control conditions and on a separate occasion after ingestion of MTP in two 1-g doses: $1 \mathrm{~h}$ before and $2 \mathrm{~h}$ after challenge. In four subjects both experiments were performed twice, bringing the total number of challenges for each condition to 12 . In five subjects antigen challenges were performed after ingestion of $\mathrm{HC}$ in two 20-mg doses given with MTP at the times stated above. This increased $\mathrm{HC}$ dose, compared with that used in the diurnal variation experiments, was necessary for full replacement because of the marked decrease in serum cortisol $t_{1 / 2}$ seen after MTP ingestion (28).

Cutaneous reaction and cortisol determination. Crossed diameters of the EPW (defined by its margin of edema) and LPR (defined by its

1. Abbreviations used in this paper: EPW, early phase wheal; HC, hydrocortisone; LPR, late phase reaction; MTP, metyrapone. clearest margin of erythema or induration) were measured at $20 \mathrm{~min}$ and $6 \mathrm{~h}$. An early phase increase of $2 \times 2 \mathrm{~mm}$ over the 6 -mm standard injection bleb and an LPR $\geq 4 \times 4 \mathrm{~mm}$ in diameter defined our threshold for positive reactions. Subthreshold reactions were recorded as measured for the EPW and as $0 \mathrm{~mm}$ for the LPR. Blood was drawn from an antecubital vein at either 3-h (phase 1 experiments) or 2-h intervals (phase 2 experiments), with serum separated by centrifugation at $3,000 \mathrm{rpm}$ and stored at $-20^{\circ} \mathrm{C}$. Cortisol determinations were made in duplicate from stored samples with the Amerlex cortisol RIA kit (Amersham Corp., Arlington Heights, IL). The range of this assay is $0-60 \mu \mathrm{g} / \mathrm{dl}$, intraassay coefficient of variation $=4.3$, interassay coefficient of variation $=6.8$. The percent cross-reactivity with other endogenous steroids is low, being highest for 11-deoxycortisol (1.8\%). MTP does not interfere with determinations of endogenous steroids but may cause over estimation of cortisol levels by immunoassay because of the increase in cross-reactive metabolites $(27,29)$.

LPR biopsies and histological analysis. Preliminary biopsies of LPRs were taken at 6, 9, and $12 \mathrm{~h}$. The 6-h time point was chosen for study based on peak clinical response and range of histopathology present. LPRs were not biopsied in the diurnal variation experiments because evening cortisol levels were found to be unpredictable in subjects faced with the threat of tissue removal. During phase 2 experiments, 10 matched pairs $(n=20)$ of 3-mm punch biopsies were taken centrally from LPR sites in five subjects. A matched pair was comprised of two biopsies, each taken separately during a control and MTP experiment, from sites in a single subject challenged with identical antigen concentrations. Two saline-injected sites were biopsied to establish a baseline histology. All biopsies were fixed in 10\% Formalin solution, stained with a hematoxylin and eosin preparation, and cut into thin sections for light microscopy. Histological analysis was based on the evaluation of seven parameters. These parameters included estimations on the presence of neutrophils, eosinophils, lymphocytes, and monocytes; their overall perivascular accumulation and interstitial migration; and their activation as assessed by leukocytoclasis. A dermatopathologist (Candace Kasper, M.D., Ph.D.), blinded to the experimental conditions, graded the biopsies using a semiquantitative scoring method. All biopsies were given a score of 0 to $3+$ for each parameter, with 0 defined as not different from baseline and $3+$ as marked or intense.

Data analysis. Single diameters of the EPW and LPR (averaged from duplicate reactions) were recorded separately for the three antigen dilutions used in our challenge model and, including cortisol values, are presented as the mean \pm SEM of all determinations made during an experimental condition. Differences were analyzed by the NeumanKeuls test for multiple comparisons of repeated measures. This test reports significance at the $P<0.05$ level only. \% without LPR denotes the number of subjects, as a percentage of the total, in whom duplicate challenges failed to elicit at least one positive LPR. Differences between experimental conditions for \% without LPR and LPR histology (based on matched biopsy scores) were analyzed by Fisher's exact test unless stated otherwise. Kwikstat (Southwestern Medical Center software program) and Statview II were used for statistical calculations.

\section{Results}

\section{Serum cortisol levels}

Diurnal variation experiments. Serum cortisol is secreted in a reproducible diurnal pattern. This was reflected in our experiments as subjects' mean morning cortisol ranged from 22 to 12 $\mu \mathrm{g} / \mathrm{dl}$ and mean evening values fell below $5 \mu \mathrm{g} / \mathrm{dl}$ (Fig. 1). At all three time points, mean evening cortisol was suppressed by $48 \%, 68 \%$, and $71 \%$ compared with morning $(P<0.05)$. A $10-20$-mg dose of $\mathrm{HC}$ given in the evening replaced mean serum cortisol with values significantly greater than those for evening experiments $(P<0.05$, all time points). These levels were also greater than those for morning experiments, though 


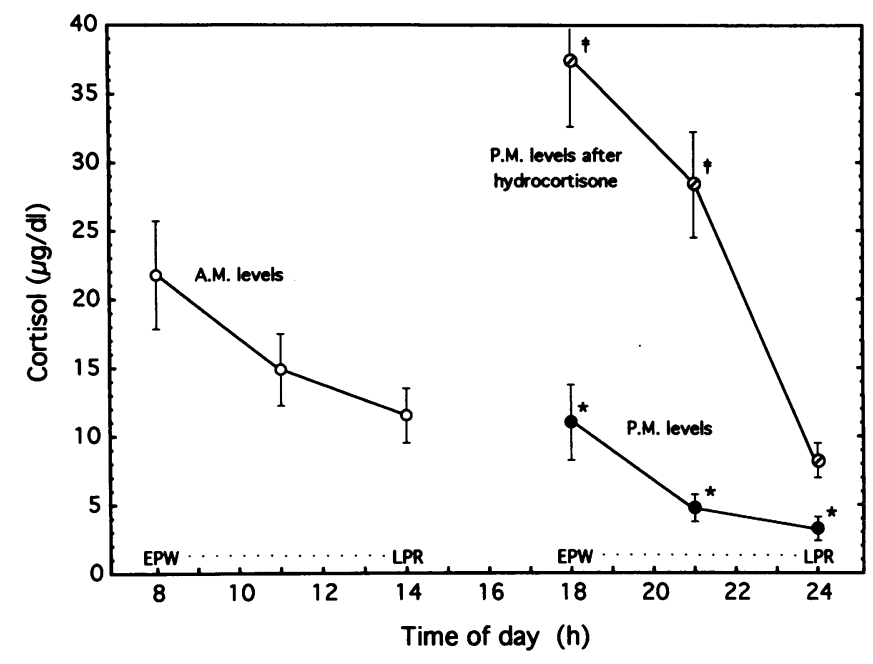

Figure 1. Diurnal variation in serum cortisol and the effect of evening hydrocortisone replacement. In antigen-challenged subjects, serum was collected at 3-h intervals and assayed for cortisol $(\mu \mathrm{g} / \mathrm{dl})$. Results are the means \pm SEM in five experiments performed at 8:00 a.m.

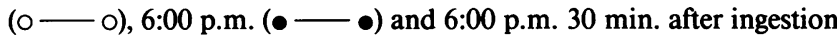
of 10-20 mg HC ( $-\odot)$. Time of antigen challenge and measurement of late phase reactions are depicted by EPW and LPR (results in Fig. 4). Compared to a.m. and p.m.+HC: ${ }^{*} P<0.05$ and compared to a.m.: ${ }^{\ddagger} P<0.05$ Neuman-Keuls test.

differences were significant only at the first two time points (Fig. 1).

Pharmacological modulation experiments. The ingestion of two 1-g doses of MTP in the morning (described in Methods) caused significant suppression of subjects' serum cortisol throughout the 6-h study period (Fig. 2). Compared with control, mean values were decreased $67.2,70.2,61.3$, and $37.7 \%$ at $0,2,4$, and $6 \mathrm{~h}$, respectively $(P<0.05)$. Similar to the evening trough in cortisol shown in Fig. 1, MTP held mean levels near

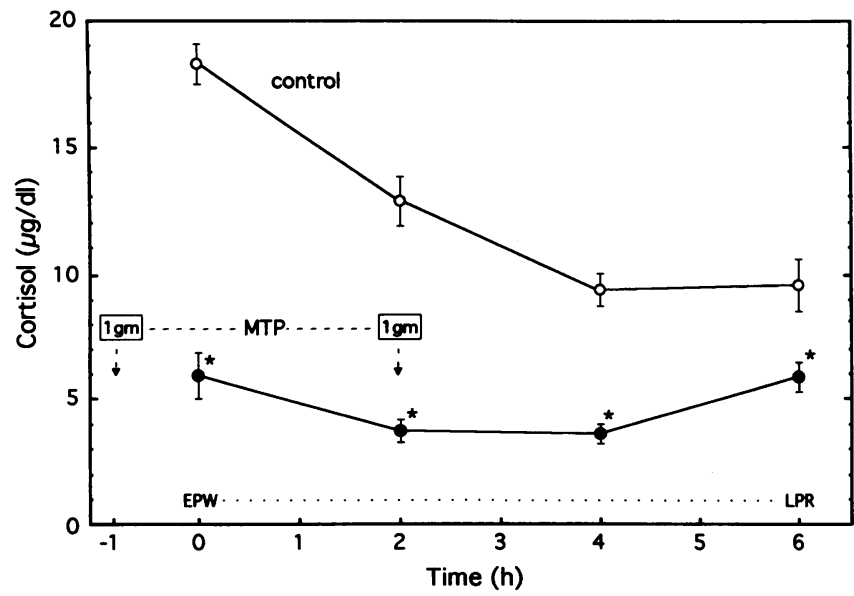

Figure 2. Metyrapone (MTP) suppression of serum cortisol. Starting between 8:00 and 9:00 a.m., serum was collected at 2-h intervals in antigen-challenged subjects and assayed for cortisol $(\mu \mathrm{g} / \mathrm{dl})$. Results are the means \pm SEM in 12 experiments performed during control conditions $(\mathrm{O}-\mathrm{O})$ and after ingestion of $2 \mathrm{~g} \operatorname{MTP}(\bullet-\bullet)$ at the indicated times. Time of antigen challenge and measurement of late phase reactions are depicted by EPW and LPR (results in Fig. 5). Compared to control: ${ }^{*} P<0.05$ Neuman-Keuls test.

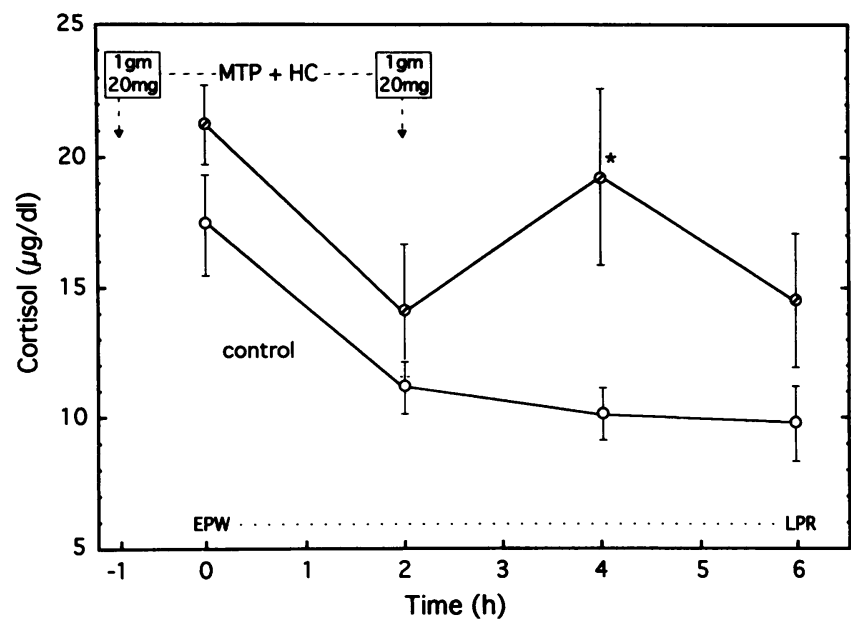

Figure 3. Effect of metyrapone (MTP) plus hydrocortisone $(H C)$ on serum cortisol levels. In antigen-challenged subjects, serum was collected at 2-h intervals beginning between 8:00 and 9:00 a.m. and assayed for cortisol $(\mu \mathrm{g} / \mathrm{dl})$. Results are the means \pm SEM in five experiments performed during control conditions $(\mathrm{O}-\mathrm{O})$ and after ingestion of $2 \mathrm{~g}$ MTP plus $40 \mathrm{mg} \mathrm{HC}(\oslash-\varnothing)$ at the indicated times. Time of antigen challenge and measurement of late phase reactions are depicted by EPW and LPR (results in Fig. 6). Compared to control: ${ }^{*} P<0.05$ Neuman-Keuls test.

or below $5 \mu \mathrm{g} / \mathrm{dl}$. When subjects took $20 \mathrm{mg}$ of $\mathrm{HC}$ with each dose of MTP (described in Methods), serum cortisol remained similar to control, although differences were significant at the 4-h time point (Fig. 3).

\section{Early phase wheal}

There were no significant differences in EPW diameters between conditions for diurnal variation or pharmacological modulation experiments (Figs. 4-6). However, EPW size did

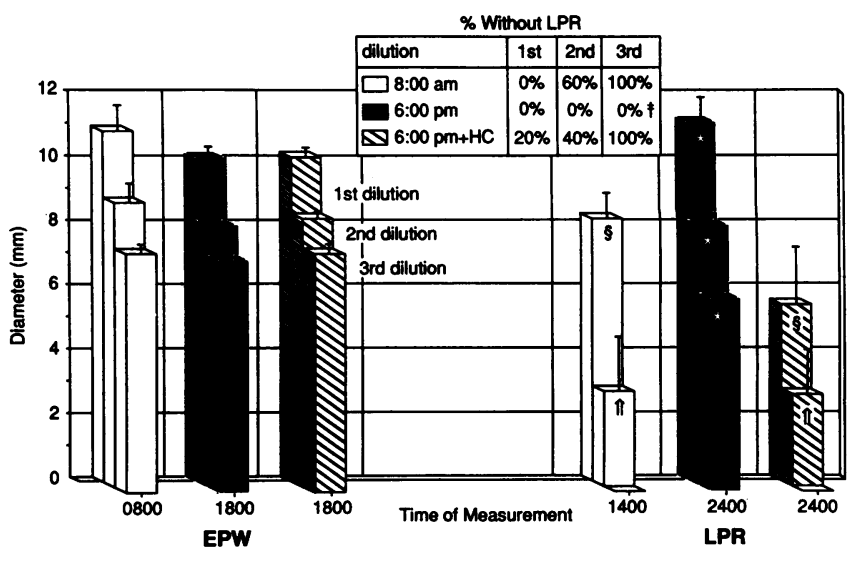

Figure 4. Diurnal variation in IgE-mediated cutaneous reactions and the effect of hydrocortisone $(H C)$ replacement. On separate occasions, subjects were challenged intradermally (with three 10 -fold serial antigen dilutions) at 8:00 a.m. (口), 6:00 p.m. (口), and 6:00 p.m. 30 min. after ingestion of 10-20 mg HC (ם). Diameters of the early phase wheal $(E P W)$ at $20 \mathrm{~min}$ and late phase reaction $(L P R)$ at $6 \mathrm{~h}$ were recorded. Results for the three antigen dilutions are shown as the means \pm SEM from five challenges. Inset shows percent of challenges by dilution that produced no LPR. Compared to a.m. and p.m. +HC: ${ }^{*} P<0.05$ Neuman-Keuls test, ${ }^{\ddagger} P \leq 0.002$ Fisher's exact test,

$\S$ "equivalent by Neuman-Keuls test. 


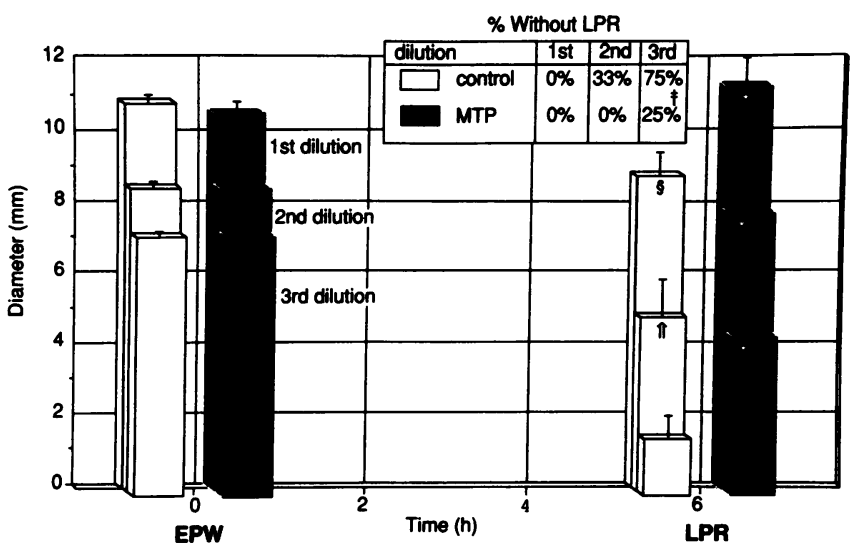

Figure 5. Effect of cortisol suppression on IgE-mediated cutaneous reactions. Between 8:00 and 9:00 a.m. subjects were challenged intradermally (with three 10-fold serial antigen dilutions) during control conditions ( $\square$ ) and during endogenous cortisol suppression by MTP (a) (cortisol levels in Fig. 2). Diameters of the early phase wheal $(E P W)$ at $20 \mathrm{~min}$ and late phase reaction $(L P R)$ at $6 \mathrm{~h}$ were recorded. Results for the three antigen dilutions are shown as the means \pm SEM from 12 challenges. Inset shows the percent of challenges by dilution that produced no LPR. Compared to control: ${ }^{*} P<0.05$ NeumanKeuls test, ${ }^{\ddagger} P \leq 0.04$ Fisher's exact test, ${ }^{\$}{ }^{\ddagger}$ equivalent by NeumanKeuls test.

demonstrate a clear dose dependence with mean diameters showing decremental reductions to the point of becoming negative (defined in Methods) as antigens were taken from the first through the third dilution (Figs. 4-6). The slope of the regression line for EPW diameter versus log antigen dilution remained consistent despite changes in serum cortisol: for morning and control challenges $y=1.9(\log x)+10.7\left(r^{2}=0.72, P\right.$ $\leq 0.0001$ ), for evening and MTP challenges $y=1.7(\log x)$ $+10.3\left(r^{2}=0.75, P \leq 0.0001\right)$, and for HC replacement challenges $y=1.6(\log x)+10.2\left(r^{2}=0.73, P \leq 0.0001\right)$.

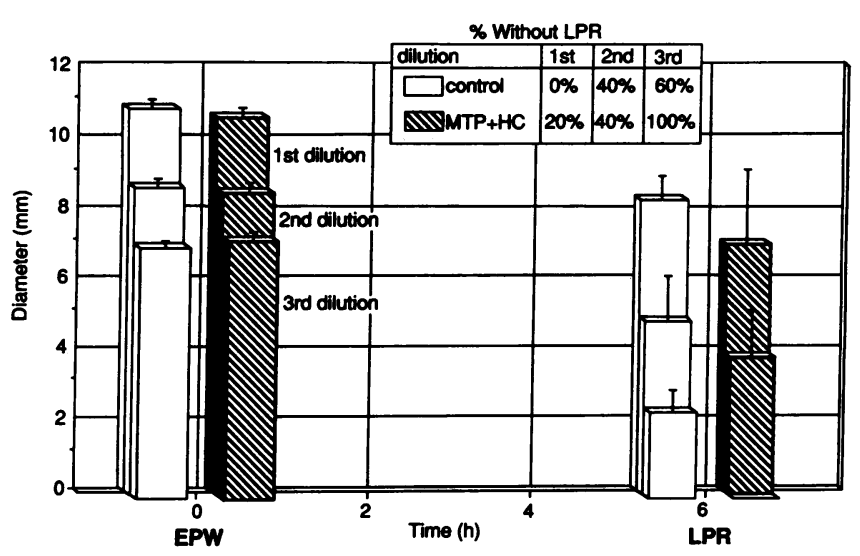

Figure 6. Effect of metyrapone $(M T P)$ plus hydrocortisone $(H C)$ on IgE-mediated cutaneous reactions. Between 8:00 and 9:00 a.m. subjects were challenged intradermally (with three 10-fold serial antigen dilutions) during control conditions ( $\square$ ) and after ingestion of MTP $+\mathrm{HC}(\varpi)$. (cortisol levels in Fig. 3). Diameters of the early phase wheal $(E P W)$ at $20 \mathrm{~min}$ and late phase reaction $(L P R)$ at $6 \mathrm{~h}$ were recorded. Results for the three antigen dilutions are shown as the means \pm SEM from five challenges. Inset shows the percent of challenges by dilution that produced no LPR.

\section{Late phase reactions}

At all three antigen dilutions, mean LPR diameters after evening and MTP challenges were significantly greater $(P<0.05)$ than those seen after morning and control challenges, respectively (Figs. 4 and 5). When subjects took replacement doses of HC during evening and MTP challenges, LPR size did not increase, and mean diameters remained equivalent to morning and control values (Figs. 4 and 6). As antigen concentrations were diluted 10 - and 100-fold the incidence of subjects without a late phase response (defined in Methods) increased from $60 \%$ to $100 \%$ in morning challenges and from $33 \%$ to $75 \%$ in control challenges (Figs. 4 and 5, inset). However, with cortisol levels suppressed in the evening or after MTP the incidence of negative reactions was significantly lower as nearly all subjects manifested a late response even at the most dilute antigen concentration ( $P \leq 0.002$, evening and $P \leq 0.04$, MTP) (Figs. 4 and 5, inset). When cortisol levels were replaced with $\mathrm{HC}$ the number of subjects without a late response was similar to that observed for morning and control challenges (Figs. 4 and 6, inset).

The use of serially diluted antigens indicated that EPW size was strongly correlated with antigen dose as described above. In all experiments we also observed a strong correlation between EPW diameter and the LPR diameter measured $6 \mathrm{~h}$ later. In morning and control experiments the slope of the regression line for LPR versus EPW diameter was nearly identical to that observed for the HC replacement experiments: $y$ $=1.8 x-11.2\left(r^{2}=0.62, P \leq 0.0001\right)$ and $y=1.8 x-12.4\left(r^{2}\right.$ $=0.53, P \leq 0.0001$ ), respectively. However, for evening and MTP experiments the regression line shifts upward: $y=1.8 x$ $-7.6\left(r^{2}=0.70, P \leq 0.0001\right)$. These same observations were seen for linear regression of LPR diameter vs. log antigen dilution indicating that the EPW intensity and antigen dose necessary for LPR expression are reduced under conditions of endogenous cortisol suppression. As presented in Figs. 4 and 5, this equates to a 10 -fold reduction in antigen concentration and the appearance of late reactions after subthreshold EPWs (isolated late phase).

\section{Histological data from LPR biopsies}

Correlation between LPR size and histological scores. Diameters of biopsied LPRs ranged from 0 to $11.5 \mathrm{~mm}$, with a mean \pm SEM of $4.3 \pm 1.3 \mathrm{~mm}$ in the control group and $8.0 \pm 0.6$ $\mathrm{mm}$ in the MTP group ( $P \leq 0.002$, paired $t$ test). A mixed-cell perivascular infiltrate defined the general histological appearance in all but one biopsy (subject 3 , third dilution, Table I), including three control biopsies where the LPR was clinically absent (subjects 1, 2 and 5, Table I). Neutrophils were the most prominent cell type identified, followed in order by eosinophils and lymphocytes; monocytes were rarely seen. As described in Methods, 20 LPR biopsies were systematically graded on seven different parameters of cutaneous inflammation. For all biopsies, the correlation between total histological score received and the measured LPR diameter was marginal by linear-regression analysis $\left(r^{2}=0.18, P=0.06\right)$. Subgrouping of parameters revealed a clear split between those that were and were not correlated with LPR size. The cumulative score for neutrophils, eosinophils, lymphocytes, monocytes, and their perivascular accumulation did not correlate $\left(r^{2}=0.09, P=0.2\right)$, whereas the cumulative score for interstitial leukocyte migration and leukocytoclasis did correlate with LPR size $\left(r^{2}=0.37\right.$, $P \leq 0.005)$. 


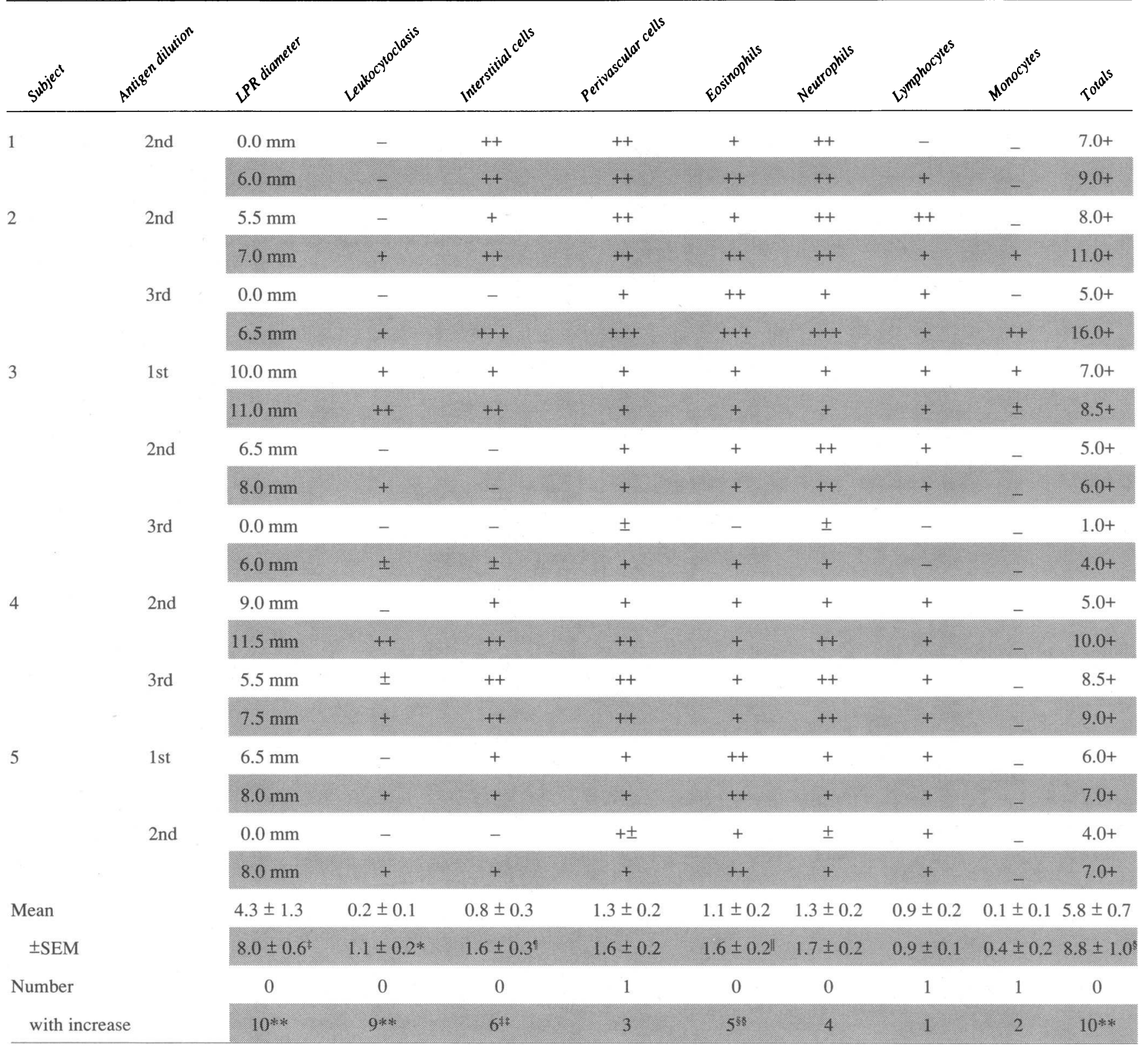

Cutaneous antigen challenges were performed during control and cortisol suppression (MTP) experiments (see Fig. 5). In five subjects matched late phase reactions (LPRs) were biopsied during each condition. A dermatopathologist blinded to the condition graded biopsies by light microscopy, using a scale of $0(-)$ to $3(+++)$, on seven parameters: 1) leukocytoclasis, 2) interstitial leukocytes, 3) perivascular leukocytes, 4) eosinophils, 5) neutrophils, 6) lymphocytes, and 7) monocytes. Subject origin and antigen dilution used appear in the first two columns. Subsequent columns list measured LPR diameter, score by parameter, and total score for biopsies from control (unshaded rows) and MTP (shaded rows) experiments. Summary data including means \pm SEM and number of matched biopsies with an increase are given at the bottom of the table. ${ }^{*} P \leq 0.0004,{ }^{\ddagger} P \leq 0.002,{ }^{8} P \leq 0.01, \| P \leq 0.02,{ }^{9} P \leq 0.03$ paired $t$ test. $\quad * * P \leq 0.0001,{ }^{\ddagger \ddagger} P \leq 0.01,{ }^{88} P \leq 0.03$ Fisher's exact test.

Comparison between control and MTP biopsies. When LPR histology was analyzed on the basis of experimental condition, all 10 MTP biopsies received a higher total score compared with their matched-control biopsy. The mean \pm SEM was $8.75 \pm 1.0$ for the MTP group versus $5.75 \pm 0.7$ for the control group $(P \leq 0.01$ paired $t$ test) (Table I). The most striking difference was seen in leukocytoclasis, as nearly all MTP biopsies $(9$ of $10, P \leq 0.0001$ ) received an increased score for this parameter. Leukocytoclasis was present in only two control biopsies and both graded lower than the matched MTP biopsy (Table I). However, a significant difference between conditions for overall inflammatory cell presence, assessed by perivascular accumulation, was not detected; nor were there significant individual differences for neutrophils, lymphocytes, and monocytes (Table I). Although overall cellularity in the MTP biopsies was not different from control, the interstitial migration of leukocytes was. Increased scores for this parameter were seen in six MTP and no control biopsies $(P \leq 0.01)$. Eosinophil presence, 
increased in five MTP vs. zero control biopsies $(P \leq 0.03)$, was the only parameter based on cell type in which differences between matched biopsies reached significance (Table I).

\section{Discussion}

This study demonstrates that changes in the physiological level of serum cortisol can affect the expression of IgE-mediated events. In experiments designed around diurnal variation and pharmacological inhibition of cortisol secretion, measurement of the biphasic response to cutaneous antigen challenge revealed that the late phase is enhanced by low levels of endogenous cortisol. Subsequent analysis of late phase biopsies identified three histological parameters that became significantly increased during cortisol-suppressed conditions, with two of these parameters indicative of activated inflammatory cells. These results suggest that regulation of the late cutaneous response by endogenous cortisol is in part directed at the activation state of cells infiltrating these reactions.

Diurnal variation in cutaneous early phase responses after mast cell activation was reported for compound 48/80 in 1965 (20) and for allergen in 1977 (21). Both studies found increased wheal reactions in the late evening when serum cortisol levels are low. In the majority of human studies, however, pharmacological doses of steroids do not appear to influence immediate mast cell responses (30-34). A recent study by Vichyanond and Nelson (35) and experiments reported here failed to detect diurnal variation in early phase responses after cutaneous antigen challenge. We also failed to see an effect from cortisol suppression initiated by metyrapone $1 \mathrm{~h}$ before antigen challenge. These findings suggest that changes in endogenous cortisol levels have little influence over the IgE-dependent release of histamine from human cutaneous mast cells.

Although current data suggest that the events governing human mast cell activation are relatively insensitive to steroid modulation, effects on other inflammatory cells are well known. In vitro, steroids have been shown to inhibit neutrophil phagocytosis and adherence; eosinophil chemotaxis, adherence, and survival; T cell proliferation, IL-2 and IL-2 receptor expression; macrophage killing, antigen presentation, IL-1, tumor necrosis factor, granulocyte macrophage colony-stimulating factor, and arachidonic acid production (for review see reference 23). The observation that steroid premedication inhibits the IgE-dependent influx of neutrophils and eosinophils and late mediator release at cutaneous late phase sites (36-38) is consistent with the functional regulation by steroids found in other immunologic systems. Clinically, steroids are potent inhibitors of allergic late phase reactions in the skin, lung, and nose (30-33). Chronic allergic disease states like asthma and perennial rhinitis are now felt to have a predominate inflammatory component, with a histopathology similar to the mixed cellular infiltrate of neutrophils, eosinophils, and mononuclear cells seen in late phase biopsies from allergic challenge models $(39,40)$. It then comes as no surprise that pharmacological doses of steroids are currently the most effective known treatment for these conditions.

In asthmatics, diurnal variation in pulmonary function has been well described and nocturnal exacerbation of symptoms is a frequent occurrence, affecting $75 \%$ of patients at least weekly in one large epidemiologic study (41). The precise mechanisms responsible for nocturnal asthma exacerbations have remained obscure, although studies can be found supporting correlations with circadian rhythms in both plasma cortisol and epinephrine $(17,18)$. Few studies have directly addressed circadian rhythms and allergic late phase inflammation; although recently, a significant diurnal variation in the late asthmatic response after antigen inhalation was observed, with increased bronchoconstriction occurring in the evening (42). In a study using experimental dogs, Sasaki et al. (6) reproduced cortisol's diurnal variation by pharmacological means and found that antigen inhalation caused late phase bronchoconstriction and peribronchial inflammatory cell infiltrates only when endogenous cortisol was suppressed by metyrapone. These previously reported observations, providing much of the impetus for our own investigations, indicate the existence of circadian variability in inflammation and the potential role played by endogenous cortisol.

The threshold for cortisol's immunosuppressive effects is not well defined; however, functional inhibition has been seen at a level of $10 \mu \mathrm{g} / \mathrm{dl}$ in at least one in vitro immunologic system (43). We observed that subjects studied in the late evening or after the ingestion of metyrapone had cortisol levels below 5 $\mu \mathrm{g} / \mathrm{dl}$, compared with values well above $10 \mu \mathrm{g} / \mathrm{dl}$ during the morning hours. This degree of cortisol suppression not only increased the mean diameter of IgE-mediated late cutaneous reactions in our subjects but also induced the appearance of isolated late reactions. Previous investigations have shown that LPR size is highly correlated with the size of the preceding EPW. Some studies demonstrated that the smallest EPW diameter, after intradermal antigen injection, associated with a late response ranged from 6 to $9.5 \pm 1 \mathrm{~mm}(44-46)$. We found this same correlation between EPW size and LPR expression in our experiments, and when mean EPW diameters fell below $8 \mathrm{~mm}$ (subthreshold) in either morning or control experiments, most subjects did not have a LPR. However, under conditions of cortisol suppression there was an upward shift in the regression line for LPR versus EPW diameter, and third-dilution challenges elicited late responses in nearly all subjects despite mean EPW diameters that were clinically negative. When replacement hydrocortisone was given with metyrapone or in the evening, serum cortisol levels were not suppressed, and we no longer saw the increases in mean LPR diameter, shifting of the LPR versus EPW regression line, or isolated late responses. Thus, evidence from diurnal variation and pharmacological modulation experiments indicates that changes in the physiological level of serum cortisol can have a significant impact on the physical expression of IgE-mediated late cutaneous inflammation.

Several investigators have reported that the cutaneous LPR is characterized by the sequential infiltration of neutrophils, eosinophils, and lymphocytes $(25,47)$. However, most studies have not found histology (with the exception of fibrin deposition) to correlate with LPR size or even differentiate positive from negative LPR sites $(45,47,48)$. LPR biopsies from our subjects uniformly demonstrated a perivascular infiltrate of neutrophils, eosinophils, and lymphocytes that also failed to correlate with the measured LPR diameter. Two histological parameters were found, leukocytoclasis and leukocyte interstitial migration, that together did correlate well with physical LPR expression. Only one other study has looked at leukocytoclasis in analyzing cutaneous LPR histology; although no correlation was found with LPR size, biopsies were performed long after (24 h) the peak of clinical inflammation (48). In our 
study direct comparison of matched biopsies (control vs. MTP) revealed minor differences in the presence of inflammatory cells, reaching significance only for eosinophils. MTP treatment has been shown to increase peripheral blood eosinophil and lymphocyte counts in humans and to decrease neutrophil counts in animals (49-51). Although effects on tissue histology from changes in peripheral blood leukocytes are less than clear, the possibility exists that histological scores from MTP biopsies could be exaggerated for eosinophils and lymphocytes or depressed for neutrophils. The use of a semiquantitative scoring method may have additionally missed subtle differences in leukocyte numbers. Striking differences were not obscured, as increased leukocytoclasis and interstitial leukocyte migration were recorded for the majority of MTP biopsies. Differences in leukocyte accumulation, significant only for eosinophils, could indicate an effect on the local release of factors involved in cellular recruitment, while increases in leukocytoclasis and interstitial migration are more likely to reflect an increased level of cellular function. The changes seen in the MTP biopsies suggest that suppression of serum cortisol enhanced the physical expression of LPRs by affecting not only inflammatory cell recruitment, but also the activation state of these infiltrating cells.

The finding in humans that blister fluid, obtained from sites up to 60 min after mast cell activation, will produce a LPR upon reinjection provides evidence that factors released by mast cells are critical for LPR expression (52). It is now clear from animal studies that mast cells secrete several cytokines after receptor activation. TNF and IL-6 mRNA appear early (within $30 \mathrm{~min}$ ), whereas mRNA for IL-1, $-3,-4$ and -5 appear several hours after mast cell stimulation (53-55). Tumor necrosis factor and IL-1 are known to increase adhesion molecule expression on human endothelial cells in vitro $(56,57)$ and, with newly formed lipid mediators such as PAF and leukotriene B4, may be responsible for the recruitment of inflammatory cells into sites of mast cell activation. However, the poor correlation between LPR size and inflammatory cell presence at biopsy seen in our study and by others $(45,47,48)$, suggests a level of interaction other than recruitment must exist between mast cells and infiltrating leukocytes. Several of the cytokines listed above are likely to play a role in this interaction. Since glucocorticoids appear to inhibit lymphocyte proliferation by blocking cytokine gene transcription (58), increased cytokine production could account for the enhanced leukocyte activation we observed in LPR biopsies from cortisol-depleted subjects.

In contrast to studies where subjects are premedicated with pharmacological doses of steroids (36-38), we did not find a striking effect on LPR cellularity based on differences in serum cortisol. There are several explanations as to why this occurred. First, the relative steroid differential obtained in our experiments is $10-20$ times less than that predicted from a $40-\mathrm{mg}$ dose of prednisone. Second, because we depleted cortisol levels only $1 \mathrm{~h}$ before antigen challenge, the early release of mast cell signals involved in leukocyte recruitment may not have been affected. Third, as stated earlier, our method of histological scoring may have missed real differences in leukocyte numbers between matched biopsies. Our results do not minimize steroid effects on inflammatory cell recruitment, but they do implicate the activation state of infiltrating cells as an important factor in late phase expression and one that appears to be regulated by endogenous cortisol.
The results of this study demonstrate that circadian variation in IgE-dependent late phase inflammation is directly related to the level of endogenous cortisol. Though, the precise nature of glucocorticoid regulation over LPRs remains speculative, endogenous cortisol should be viewed as a powerful force that can affect inflammatory events after mast cell activation in a variety of disease states.

\section{Acknowledgments}

We thank Sue Bennett and her associates in the Freeman pathology lab for processing and preparation of biopsies; Tod Kimbell, Eric Radjef, and Eric Casey for assistance with experiments; Tad Herrscher for legal advice; and Christy Bartlett for the long hours required in manuscript preparation.

\section{References}

1. Seyle, H. 1946. The general adaptation syndrome and the diseases of adaptation. J. Clin. Endocrinol. 6:117-230.

2. Ingle, D. J. 1952. The role of the adrenal cortex in homeostasis. J. Endocrinol. 8:xxiii-xxxvii.

3. Hench, P. S., E. C. Kendall, C. H. Slocumb, and H. F. Polley. 1949. The effect of a hormone of the adrenal cortex (17-hydroxy-11-dehydrocorticosterone: compound E) and of pituitary adrenocorticotropic hormone on rheumatoid arthritis. Proc. Staff Meet. Mayo Clin. 24:181-197.

4. Sayers, G. 1950. The adrenal cortex and homeostasis. Physiol. Rev. 30:241320.

5. Munck, A., P. M. Guyre, and N. J. Holbrook. 1984. Physiologic functions of glucocorticoids in stress and their relation to pharmacologic actions. Endocr. Rev. 5:25-44.

6. Sasaki, H., M. Yanai, S. Shimura, H. Okayama, T. Aikawa, and T. Takishima. 1987. Late asthmatic response to ascaris antigen challenge in dogs treated with metyrapone. Am. Rev. Respir. Dis. 136:1459-1465.

7. Besedovsky, H. O., A. del Rey, and E. Sorkin. 1979. Antigenic competition between horse and sheep red blood cells as a hormone-dependent phenomenon. Clin. Exp. Immunol. 37:106-113.

8. Sternberg, E. M., J. M. Hill, G. P. Chrousos, T. Kamilaris, S. J. Listwak, P. W. Gold, and R. L. Wilder. 1989. Inflammatory mediator-induced hypothalamic-pituitary-adrenal axis activation is defective in streptococcal cell wall arthritis-susceptible Lewis rats. Proc. Natl. Acad. Sci. USA. 86:2374-2378.

9. Rothwell, P. M., Z. F. Udwadia, and P. G. Lawler. 1991. Cortisol response to corticotropin and survival in septic shock. Lancet. 337:582-583.

10. Besedovsky, H. O., A. del Rey, and E. Sorkin. 1981. Lymphokine-containing supernatents from con A-stimulated cells increase corticosterone blood levels. J. Immunol. 126:385-387.

11. Berkenbosch, F., J. Van Oers, A. Del Ray, F. Tilders, and H. Besedovsky 1987. Corticotropin-releasing factor-producing neurons in the rat activated by interleukin-1. Science (Wash. DC). 238:524-526.

12. Bernardini, R., T. C. Kamilaris, A. E. Calogero, E. O. Johnson, M. T. Gomez, P. W. Gold, and G. P. Chrousos. 1990. Interactions between tumor necrosis factor- $\alpha$, hypothalamic corticotropin-releasing hormone, and adrenocorticotropin secretion in the rat. Endocrinology. 126:2876-2881.

13. Navarra, P., S. Tsagarakis, M. S. Faria, L. H. Rees, G. M. Besser, and A. B. Grossman. 1991. Interleukins-1 and -6 stimulate the release of corticotropin-releasing hormone-41 from rat hypothalamus in vitro via the eicosanoid cyclooxygenase pathway. Endocrinology. 128:37-44.

14. Weitzman, E. D., D. Fukushima, C. Nogeire, H. Roffwarg, T. F. Gallagher, and L. Hellman. 1971. Twenty-four hour pattern of the episodic secretion of cortisol in normal subjects. J. Clin. Endocrinol. Metab. 33:14-22.

15. Reed, C. E. 1988. Basic mechanisms of asthma, role of inflammation. Chest. 94:175-177.

16. Clark, T. J. H., and M. R. Hetzel. 1977. Diurnal variation of asthma. Br. J Dis. Chest. 71:87-92.

17. Kallenbach, J. M., V. R. Panz, B. I. Joffe, D. Jankelow, R. Anderson, B. Haitas, and H. C. Seftel. 1988. Nocturnal events related to morning dipping in bronchial asthma. Chest. 93:751-757.

18. Barnes, P., G. Fitzgerald, M. Brown, and C. Dollery. 1980. Nocturnal asthma and changes in circulating epinephrine, histamine, and cortisol. New Engl. J. Med. 303:263-267.

19. Soutar, C. A., J. Costello, O. Ijaduola, and M. Turner-Warwick. 1975. Nocturnal and morning asthma: relationship to plasma corticosteroids and response to cortisol infusion. Thorax. 30:436-440.

20. Reinberg, A., P. Gervais, F. Levi, M. Smolensky, L. Del Cerro, and C. Ugolini. 1988. Circadian and circannual rhythms of allergic rhinitis: an epidemio- 
logic study involving chronobiologic methods. J. Allergy Clin. Immunol. 81:5162.

21. Lee, R. E., M. H. Smolensky, C. S. Leach, and J. P. McGovern. 1977 Circadian rhythms in the cutaneous reactivity to histamine and selected antigens, including phase relationship to urinary cortisol excretion. Ann. Allergy. 38:231236.

22. Reinberg, A., E. Sidi, and J. Ghata. 1965. Circadian reactivity rhythms of human skin to histamine or allergen and the adrenal cycle. J. Allergy. 36:273283.

23. Schleimer, R. P. 1990. Effects of glucocorticosteroids on inflammatory cells relevant to their therapeutic applications in asthma. Am. Rev. Respir. Dis. 141:S59-S69.

24. Solley, G. O., G. J. Gleich, R. E. Jordan, and A. L. Schroeter. 1976. The late phase of the immediate wheal and flare reaction. Its dependence upon IgE antibodies. J. Clin. Invest. 58:408-420.

25. Atkins, P. C., G. R. Green, and B. Zweiman. 1973. Histologic studies of human skin test responses to ragweed, compound $48 / 80$ and histamine. J. Allergy Clin. Immunol. 51:263-273.

26. Lemanske, R. F., Jr., and M. Kaliner. 1988. Late-phase IgE-mediated reactions. J. Clin. Immunol. 8:1-13.

27. Liddle, G. W., D. Island, E. M. Lance, and A. P. Harris. 1958. Alterations of adrenal steroid patterns in man resulting from treatment with a chemical inhibitor of $11 \beta$-hydroxylation. J. Clin. Endocrinol. 18:906-912.

28. Bruno, O. D., R. Leclercq, E. Virasoro, and G. Copinschi. 1971. Extraadrenal actions of metyrapone in man. Effects on plasma cortisol disappearance, growth hormone secretion and glucose metabolism. J. Clin. Endocrinol. 32:260265.

29. Canalis, E., A. M. Caldarella, and G. E. Reardon. 1979. Serum cortisol and 11 deoxycortisol by liquid chromatography: clinical studies and comparison with radioimmunoassay. Clin. Chem. 25:1700-1703.

30. Poothullil, J., L. Umemoto, J. Dolovich, F. E. Hargreave, and R. P. Day 1976. Inhibition by prednisone of late cutaneous allergic responses induced by antiserum to human IgE. J. Allergy Clin. Immunol. 57:164-167.

31. Gronneberg, R., K. Strandberg, G. Stalenheim, and O. Zetterstrom. 1981. Effect in man of anti-allergic drugs on the immediate and late phase cutaneous allergic reactions induced by anti-IgE. Allergy. 36:201-208.

32. Pipkorn, U., D. Proud, L. M. Lichtenstein, R. P. Schleimer, S. P. Peters, N. F. Adkinson, Jr., A. Kagey-Sobotka, P. S. Norman, and R. M. Naclerio. 1987. Effect of short-term systemic glucocorticoid treatment on human nasal mediator release after antigen challenge. J. Clin. Invest. 80:957-961.

33. Nakazawa, T., T. Toyoda, M. Furukawa, T. Taya, and S. Kobayashi. 1976. Inhibitory effects of various drugs on dual asthmatic responses in wheat flour sensitive subjects. J. Allergy Clin. Immunol. 58:1-9.

34. Cohan, V. L., B. J. Undem, C. C. Fox, N. F. Adkinson, Jr., L. M. Lichtenstein, and R. P. Schleimer. 1989. Dexamethasone does not inhibit the release of mediators from human mast cells residing in airway, intestine or skin. Am. Rev. Respir. Dis. 140:951-954.

35. Vichyanond, P., and H. S. Nelson. 1989. Circadian variation of skin reactivity and allergy skin tests. J. Allergy Clin. Immunol. 83:1101-1106.

36. Mancini, R. E., P. A. Colombi, H. Galli, and L. Orciuoli. 1961. Effect of glucocorticoid hormones on experimentally induced allergic reactions on human skin. J. Allergy. 32:471-482.

37. Zweiman, B., R. I. Slott, and P. C. Atkins. 1976. Histologic studies of human skin test responses to ragweed and compound 48/80. J. Allergy Clin. Immunol. 58:408-420.

38. Charlesworth, E. N., A. Kagey-Sobotka, R. P. Schleimer, P. S. Norman, and L. M. Lichtenstein. 1991. Prednisone inhibits the appearance of inflammatory mediators and the influx of eosinophils and basophils associated with the cutaneous late-phase response to allergen. J. Immunol. 146:671-676.

39. Wardlaw, A. J., S. Dunnette, G. J. Gleich, J. V. Collins, and A. B. Kay.
1988. Eosinophils and mast cells in bronchoalveolar lavage in subjects with mild asthma: relationship to bronchial hyperreactivity. Am. Rev. Respir. Dis. 137:6269.

40. Beasley, R., W. R. Roche, J. A. Roberts, and S. T. Holgate. 1989. Cellular events in the bronchi in mild asthma and after bronchial provocation. Am. Rev. Respir. Dis. 139:806-817.

41. Turner-Warwick, M. 1988. Epidemiology of nocturnal asthma. Am. J. Med. 85(S1B):6-8.

42. Mohiuddin, A. A., and R. J. Martin. 1990. Circadian basis of the late asthmatic response. Am. Rev. Respir. Dis. 142:1153-1157.

43. Weller, F. R., H. H. Weller, C. G. M. Kallenberg, T. H. The, and N. G. M. Orie. 1986. Sensitivity to hydrocortisone is a relevant factor in the immunoendocrine relationship. J. Allergy Clin. Immunol. 78:423-430.

44. Umemoto, L., J. Poothullil, J. Dolovich, and F. E. Hargreave. 1976. Factors which influence late cutaneous allergic responses. J. Allergy Clin. Immunol. 58:60-68.

45. Deshazo, R. D., A. I. Levinson, H. F. Dvorak, and R. W. Davis. 1979. The late phase skin reaction: evidence for activation of the coagulation system in an IgE-dependent reaction in man. J. Immunol. 122:692-698.

46. Dolovich, J., F. E. Hargreave, R. Chalmers, K. J. Shier, J. Gauldie, and J. Bienenstock. 1973. Late cutaneous allergic responses in isolated IgE-dependent reactions. J. Allergy Clin. Immunol. 52:38-46.

47. Frew, A. J., and A. B. Kay. 1988. The relationship between infiltrating CD4+ lymphocytes, activated eosinophils, and the magnitude of the allergen-induced late phase cutaneous reaction in man. J. Immunol. 141:4158-5164.

48. Richerson, H. B., D. Rajtora, G. Penick, F. R. Dick, T. J. Yoo, J. K. Kammermeyer, and J. S. Anuras. 1979. Cutaneous and nasal allergic responses in ragweed hayfever: lack of clinical and histopathological correlation with late phase reactions. J. Allergy Clin. Immunol. 64:67-77.

49. Kaalund Jensen, H., and M. Blichert-Toft. 1971. Investigation of pituitary-adrenocortical function in the elderly during standardized operations and postoperative intravenous metyrapone test assessed by plasma cortisol, plasma compound S and eosinophil cell determinations. Acta Endocrinol. 67:495-507.

50. Britton, S., M. Thoren, and H. E. Sjoberg. 1975. The immunological hazard of Cushing's syndrome. Br. Med. J. 4:678-680.

51. Patt, J. A., and R. J. Eberhart. 1977. Total and differential leukocyte counts in cesarean-derived newborn pigs following treatment with ACTH or metyrapone. Am. J. Vet. Res. 38:793-797.

52. Dorsch, W., and J. Ring. 1981. Induction of late cutaneous reactions by skin-blister fluid from allergen-tested and normal skin. J. Allergy Clin. Immunol. 67:117-123.

53. Gurish, M. F., N. Ghildyal, J. Arm, K. F. Austen, S. Avraham, D. Reynolds, and R. L. Stevens. 1991. Cytokine mRNA are preferentially increased relative to secretory granule protein mRNA in mouse bone marrow-derived mast cells that have undergone IgE-mediated activation and degranulation. J. Immunol. 146:1527-1533.

54. Gordan, J. R., and S. J. Galli. 1990. Mast cells as a source of both preformed and immunologically inducible TNF- $\alpha$ /cachectin. Nature (Lond.). 346:274-276.

55. Gordan, J. R., P. R. Burd, and S. J. Galli. 1990. Mast cells as a source of multifunctional cytokines. Immunol. Today. 11:458-464.

56. Pober, J. S., M. A. Gimbrone, Jr., L. A. Lapierre, D. L. Mendrick, W. Fiers, R. Rothlein, and T. A. Springer. 1986. Overlapping patterns of activation of human endothelial cells by interleukin 1, tumor necrosis factor, and immune interferon. J. Immunol. 137:1893-1896.

57. Thornhill, M. H., and D. O. Haskard. 1990. IL-4 regulates endothelial cell activation by IL-1, tumor necrosis factor, or IFN- $\gamma$. J. Immunol. 145:865-872.

58. Almawi, W. Y., M. L. Lipman, A. C. Stevens, B. Zanker, E. T. Hardo, and T. B. Strom. 1991. Abrogation of glucocorticosteroid-mediated inhibition of Tcell proliferation by the synergistic action of IL-1, IL-6, and IFN- $\gamma$. J. Immunol. 146:3523-3527. 